\title{
RADIOCARBON DATING OF LUMPS FROM AERIAL LIME MORTARS AND PLASTERS: METHODOLOGICAL ISSUES AND RESULTS FROM SAN NICOLÒ OF CAPODIMONTE CHURCH (CAMOGLI, GENOA, ITALY)
}

\author{
G Pesce $^{1,2} \bullet$ G Quarta $^{3} \bullet$ L Calcagnile $^{3} \bullet \mathrm{M} \mathrm{D}^{\prime}$ Elia $^{3} \bullet \mathrm{P} \mathrm{Cavaciocchi}^{4} \bullet \mathrm{C}_{\text {Lastrico }}{ }^{1} \bullet$ R Guastella $^{4}$
}

ABSTRACT. This paper deals with the potentialities and technical and methodological issues associated with the use of lumps of not completely melted lime as material suitable for the radiocarbon dating of aerial lime mortars and plasters. In fact, the identification and selection of single aggregates of unmelted lumps allows one to reduce the possible contamination resulting from external sources of carbon such as " ${ }^{14} \mathrm{C}$-dead" limestone in sand added to the mixture during preparation. This procedure results in the possibility for accurate ${ }^{14} \mathrm{C}$ determinations from single pieces of masonry, supplying important information about the construction phases of historical buildings. The potential of this approach is shown by presenting the results of the archaeological study on the walls of San Nicolò of Capodimonte church (Camogli, Genoa, Italy), where this technique has been successfully applied to obtain absolute ages of different parts of the building. The obtained results were then compared with the information gathered from historical sources and with stratigraphic and other archaeological studies.

\section{INTRODUCTION}

Within the restoration works of the San Nicolò church of Capodimonte (Camogli, Genoa, Italy), a medieval church on Portofino Mountain with a crux commissa plan, a multidisciplinary study has been carried out for the analysis of principal construction stages of this striking religious building. The study included archaeological analysis of the walls, research of bibliographic sources, and accelerator mass spectrometry (AMS) radiocarbon dating of mortar samples. Archaeological evidences and bibliographic sources suggest that the church was originally set up in the 11th century, and underwent some major changes of its structure during the 12th and 13th centuries. Nevertheless, the lack of detailed documentation about the different construction phases suggested that a more direct and absolute dating method was highly desirable.

The first, and more obvious, solution of dating charred or other organic remains found in the mortar was discarded, mostly because the amount of organic residues found in the selected samples was not enough for ${ }^{14} \mathrm{C}$ dating and also because the age of these kind of samples do not necessarily reflect the age of construction of the building (Tubbs and Kinder 1990). Thus, the direct dating of the mortar would allow to overcome these problems. In fact, the use of mortar as material for ${ }^{14} \mathrm{C}$ dating has been exploited for a long time (Folk and Valastro 1976; Pachiaudi et al. 1986; Van Strydonck et al. 1992; Berger 1992; Heinemeier et al. 1997; Ringbom et al. 2003; Sonninen and Jungner 2001; Nawrocka et al. 2005; Lindroos et al. 2007). The basic principle of the method is quite simple. Mortar is produced from limestone (essentially $\mathrm{CaCO}_{3}$, calcium carbonate) of geological origin ("dead" in terms of ${ }^{14} \mathrm{C}$ concentration), which, in the past, was burned at $\angle 900{ }^{\circ} \mathrm{C}$ to produce $\mathrm{CaO}$ (quicklime). Mortar was then created by slaking the $\mathrm{CaO}$ with water and mixing it with sand (aggregates). When in place, mortars (essentially formed by $\mathrm{Ca}(\mathrm{OH})_{2}+$ aggregates) hardens by adsorbing $\mathrm{CO}_{2}$ from the atmosphere and becoming again calcium carbonate $\left(\mathrm{Ca}(\mathrm{OH})_{2}+\mathrm{CO}_{2} \rightarrow \mathrm{CaCO}_{3}+\mathrm{H}_{2} \mathrm{O}\right)$. As a result of this process, the calcium carbonate contained in the mortar reflects the atmospheric ${ }^{14} \mathrm{C}$ concentration at the time of hardening, and thus can be used as material for ${ }^{14} \mathrm{C}$ dating. Nevertheless, although very simple in its principles, several studies have shown the drawbacks and limi-

\footnotetext{
${ }^{1}$ Institute of the History of Material Culture (ISCUM), 35r, Sarzano Square, 16128 Genoa, Italy.

${ }^{2}$ Corresponding author. Email: gianluca.pesce@ gmail.com.

${ }^{3}$ CEDAD, Centre for Dating and Diagnostics, Department of Engineering of Innovation, University of Salento, Lecce, Italy.

${ }^{4}$ Freelance architect.
}

(C) 2009 by the Arizona Board of Regents on behalf of the University of Arizona

Proceedings of the 5th International ${ }^{14} \mathrm{C}$ and Archaeology Symposium, edited by Irka Hajdas et al.

RADIOCARBON, Vol 51, Nr 2, 2009, p 867-872 
tations of the method (Van Strydonck et al. 1986), which are due to contamination of the samples from carbonaceous substances such as incompletely, ${ }^{14} \mathrm{C}$-dead, burned lime and aggregates of fossil origin. Although more recent studies have shown that accurate sample selection procedures and sample processing treatments allow to significantly reduce these error sources, a different procedure is suggested in this study by selecting samples of not completely mixed lime found in the lime mor$\operatorname{tar}$ (Gallo 2001; Fieni 2002; see also Lindroos et al. 2007 for the behavior of lime lumps in a ${ }^{14} \mathrm{C}$ dating context).

\section{METHODS AND SAMPLE DESCRIPTION}

Historical sources show that during old building projects, clods of calcium oxide, taken out from the kiln after limestone burning, were immersed in a pool where the moisturizing of oxide and its dissolution to calcium hydroxide was carried out. This process was made easier by a continuous, manual mixing done with characteristic tools. This process was aimed to the complete dissolution of the clods and to the production of "lime putty," which was then mixed with sand and aggregates to produce the mortar. During this process, some small lumps of calcium hydroxide could remain compact while being mixed with the sand into the mortar. These lumps, with their characteristic hardness and white color, are clearly distinguishable inside mortars or plasters (Figure 1), from the sand grains. During the hardening of mortar, atmospheric $\mathrm{CO}_{2}$ is fixed in the lump to form calcium carbonate in the same manner as the mortar matrix. These samples are thus also suitable for ${ }^{14} \mathrm{C}$ dating, but are much less sensitive to contamination than the mortar since they can be easily distinguished from the mortar matrix and from the aggregates.

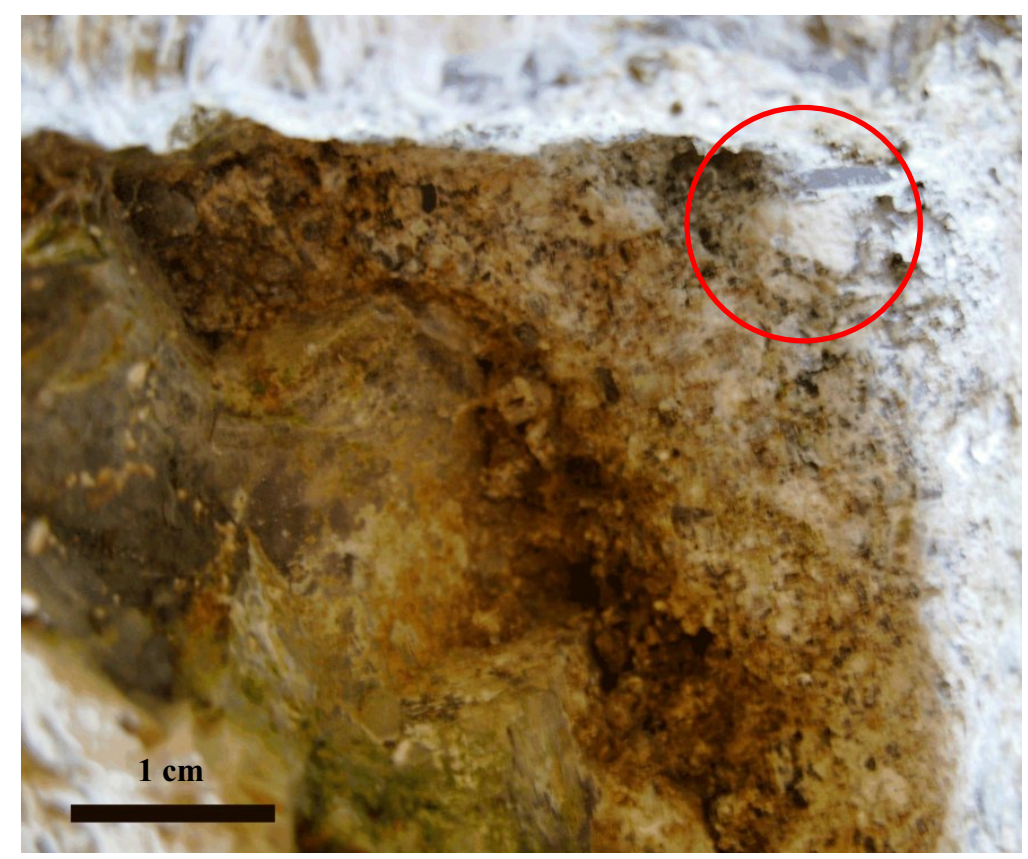

Figure 1 Mortar joint with lump of lime (upper right corner, circled)

This method for dating building structures was then applied for the ${ }^{14} \mathrm{C}$ dating of the mortars of San Nicolò of Capodimonte church by selecting 2 samples of lumps and 1 sample of charcoal. Sampling of lumps has been possible through the large joint of mortar ( $>1 \mathrm{~cm}$ thickness), which is character- 
istic of the building technique, and through some damaged masonry. Sampling was done 1-2 cm inside the wall, assuring that enough calcium carbonate $(\sim 20 \mathrm{mg})$ was collected for ${ }^{14} \mathrm{C}$ dating.

The first sample (LTL2133A) was picked next to the interior border of the apsidal basin, on the right-hand side of the transept; the lump was a fine white powder. The second sample (LTL2978A) was picked from the external face of a wall, under the same apsidal basin. The sample of charcoal (LTL2132A) was picked from the internal face of the main apse. Although the stratigraphic position of the 2 samples was clear, the position of the third sample (the charcoal) was not perfectly established: it could be a part of the mortar used for the construction of wall, or a residual part of a more recent plaster applied on the interior face of the wall.

\section{MATERIALS AND METHODS}

The selected samples were then submitted for AMS ${ }^{14} \mathrm{C}$ dating at CEDAD (Centre for Dating and Diagnostics), University of Salento, Lecce, Italy (Calcagnile et al. 2005). The selected carbonate samples (LTL2133A and LTL2978A) underwent the standard processing procedure used for carbonates, consisting of a preliminary mechanical cleaning with an optical microscope for the removal of macro-contaminants (Figure 2) followed by treatment with $30 \% \mathrm{H}_{2} \mathrm{O}_{2}$ in an ultrasonic bath to eliminate the sample's external layer. Some 8-10 mg of the precleaned samples, dried in an oven at $60{ }^{\circ} \mathrm{C}$ for $8 \mathrm{hr}$, were then treated with ultra-high-purity $15 \% \mathrm{H}_{2} \mathrm{O}_{2}$ and then converted to $\mathrm{CO}_{2}$ in quartz ampoules by using $\mathrm{H}_{3} \mathrm{PO}_{4}$. The charcoal sample (LTL2132A) was treated by using the AAA (acid-alkali-acid) protocol and converted to $\mathrm{CO}_{2}$ by combustion at $900{ }^{\circ} \mathrm{C}$ in sealed quartz tubes together with $\mathrm{CuO}$ and silver wool. The $\mathrm{CO}_{2}$ extracted from the samples, cryogenically purified, was finally reduced to graphite at $600{ }^{\circ} \mathrm{C}$ by using $\mathrm{H}_{2}$ as the reducing medium and iron powder as catalyst. Finally, the obtained graphite was pressed in the target holders of the accelerator mass spectrometer for measurement of the carbon isotopic ratios. IAEA (International Atomic Energy Agency) C6 sucrose standard with a nominal ${ }^{14} \mathrm{C}$ concentration of $150.61 \mathrm{pMC}$ and $\mathrm{C} 1$ Carrara marble with a nominal ${ }^{14} \mathrm{C}$ content of $0 \mathrm{pMC}$ were used as standard for normalization and for estimation of the measurement and sample processing background, respectively.

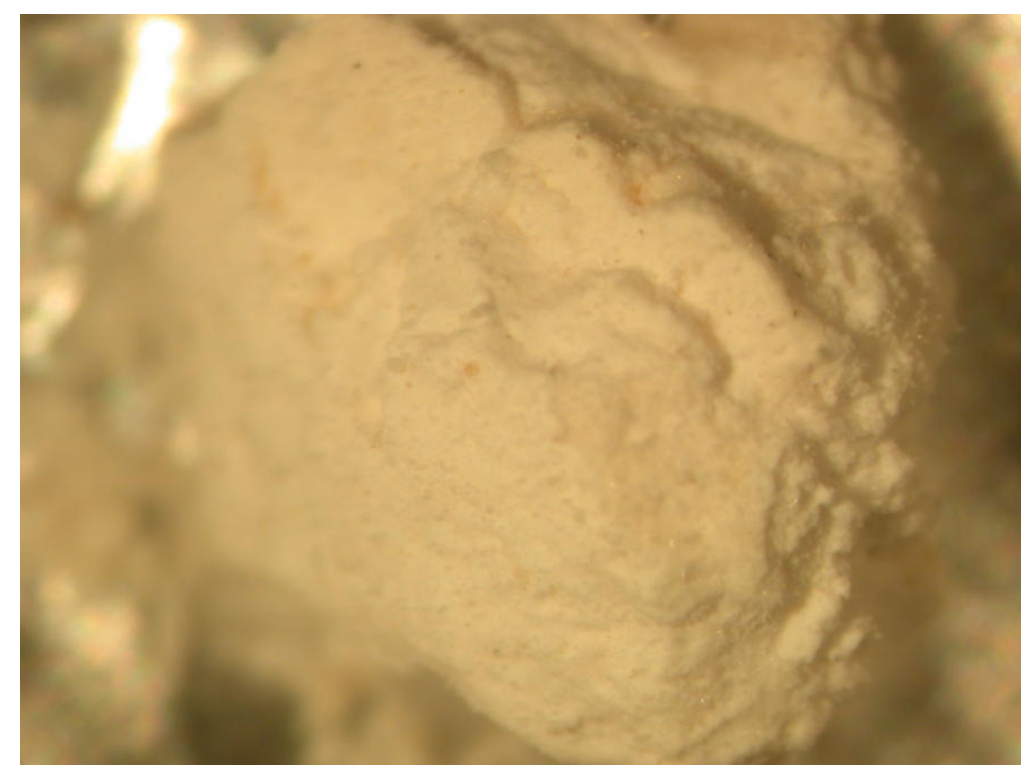

Figure 2 Image of a lump of lime taken with an optical microscope 


\section{RESULTS AND DISCUSSION}

The uncalibrated ${ }^{14} \mathrm{C}$ ages are listed in Table 1 for all analyzed samples, while the calibrated ages are shown in Figure 3 as obtained by using the software OxCal v 4.0 (Bronk Ramsey 1995, 2001) and the IntCal04 atmospheric calibration curve (Reimer et al. 2004).

Table 1 Analyzed samples and measured ${ }^{14} \mathrm{C}$ age.

\begin{tabular}{llr}
\hline Sample ID & Sample material & \multicolumn{1}{c}{${ }^{14} \mathrm{C}$ age } \\
\hline LTL2133A & Lump & $917 \pm 55 \mathrm{BP}$ \\
LTL2978A & Lump & $1005 \pm 45 \mathrm{BP}$ \\
LTL2132A & Charcoal & $790 \pm 60 \mathrm{BP}$ \\
\hline
\end{tabular}
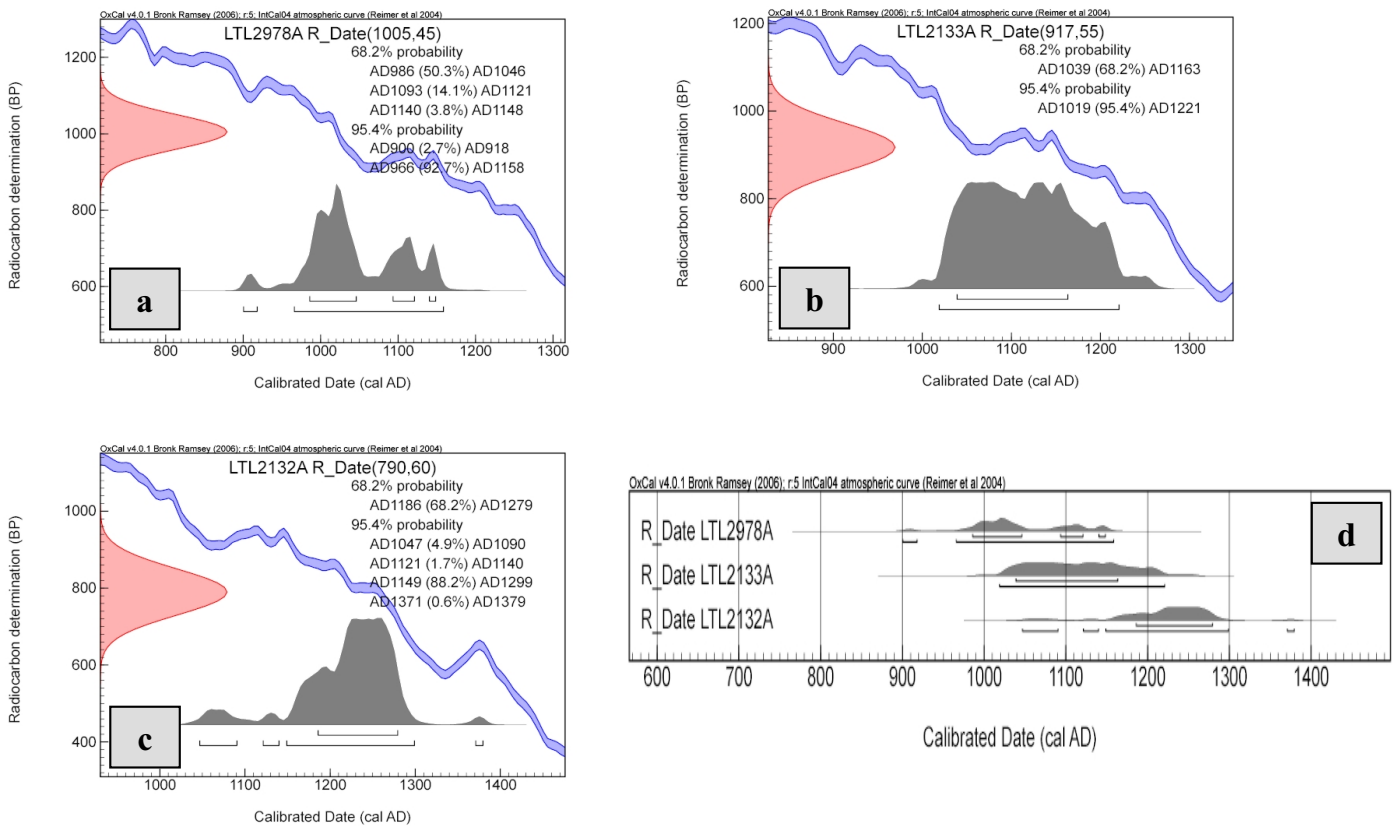

Figure 3 Calibration of the ${ }^{14} \mathrm{C}$ ages obtained for the 3 samples

The analysis of ${ }^{14} \mathrm{C}$ data shows that the obtained ages are consistent with each other, with their stratigraphic position, and with the information obtained from historical sources. In fact, the archaeological analysis led to the identification of 3 main building phases, all of them dated to the Middle Ages. Bibliographic sources reveal that the church existed at least in the 12th century AD, when 2 congregations of monks did some work on the building, while the last documented construction phase can be dated to the 13th century AD. The first sample of lump (LTL2978A) was selected from structures of unknown age but stratigraphically older than the 12th century building, while sample LTL2133A was selected from church structures archaeologically dated to the 12th century. The charcoal sample (LTL2932A) has been ascribed to the last construction phase of the building dated to the 13th century AD based on the typology of the walls and on the dimensions of stones (an archaeological dating method).

The obtained ${ }^{14} \mathrm{C}$ results confirm overall the expected ages of the samples and their stratigraphic position. Sample LTL2978A is ${ }^{14} \mathrm{C}$ dated to between the end of the 10th and the middle of the 12th 
century cal AD, sample LTL2133A to the 11th-12th century cal AD, and the charcoal sample to the last construction phase of the building in the 13th century cal AD.

The obtained results for the lump samples are thus very promising for the application of the method for direct absolute dating of mortars. However, some issues still need to be addressed such as the quite large calendar time ranges resulting from calibration of the conventional ${ }^{14} \mathrm{C}$ ages and the problems associated with sampling. In fact, the first problem is strictly related to the shape of the calibration curve in the studied temporal range. Nevertheless, the application of advanced statistical tools, such as Bayesian-based methods, to constrain ${ }^{14} \mathrm{C}$ determination with stratigraphic or historical information can be expected to be of fundamental help to reduce calendar time ranges. In sampling, the use of lumps as source of carbon for ${ }^{14} \mathrm{C}$ dating shows some important issue such as

1. Problems related to the origin of the samples: they must be always sampled after a detailed stratigraphic analysis of the building structures in order to identify homogeneous part of the walls (stratigraphic units) referring to a single building phase;

2. Problems related to the in situ sampling phase arising from:

- The thickness of mortar joints (depending on the characteristics of masonry), which must be large enough to allow for selection of suitable samples. This problem is less relevant when the wall section is accessible, as for example, in the case of masonry found during archaeological excavations;

- The sampling inside the wall, which must be deep enough to avoid sampling of mortars or plasters not belonging to the original construction phase (like some plasters applied on the walls after their construction), but low enough to allow the occurrence of the carbonation process of calcium hydroxide. In fact, in some cases, not carbonated or partially carbonated samples can be found inside the walls. Consequently, the possibility to have "delayed" carbonation with respect to the construction phase should be taken into account;

- The mass of the single lump has to be evaluated directly in situ in order to have enough material for ${ }^{14} \mathrm{C}$ dating. When a single sample is not enough, the possibility to collect more than 1 sample from the same stratigraphic unit has to be evaluated;

- The presence of white lumps, very similar to the lumps useful for the ${ }^{14} \mathrm{C}$ dating but not formed by carbonated hydroxide and thus not suitable for ${ }^{14} \mathrm{C}$ dating. Examples of these kinds of lumps are calcium-silicate compounds coming from the white, weakly hydraulic lime and the residual lumps of fossil limestone not fully decomposed during the burning process.

\section{CONCLUSIONS}

${ }^{14} \mathrm{C}$ dating of lumps of calcium carbonate formed by a carbonation process of a mixture containing aerial lime is an interesting method for absolute dating of ancient buildings. The potential of the method for absolute age determination of the construction phase of historical buildings has been discussed together with some still unresolved issues related to the definition of proper sampling strategies. Nevertheless, applying the method for the age determination of the construction phases of the Capodimonte church has shown very promising results, consistent with the available historical sources and the archaeological information obtained from stratigraphic analyses of the structures.

\section{ACKNOWLEDGMENTS}

The authors are thankful to Marina Porto Antico s.r.l., sponsor of this restoration work, and to colleagues at the Institute for the History of Material Culture (ISCUM, Genoa) for their helpful support. 


\section{REFERENCES}

Berger R. 1992. ${ }^{14} \mathrm{C}$ dating mortar in Ireland. Radiocarbon 34(3):880-9.

Bronk Ramsey C. 1995. Radiocarbon calibration and analysis of stratigraphy: the OxCal program. Radiocarbon 37(2):425-30.

Bronk Ramsey C. 2001. Development of the radiocarbon calibration program. Radiocarbon 43(2A):355-63.

Calcagnile L, Quarta G, D'Elia M. 2005. High resolution accelerator based mass spectrometry: precision, accuracy and background. Applied Radiation and Isotopes 62(4):623-9.

Fieni L. 2002. La Basilica di San Lorenzo Maggiore a Milano tra età tardoantica e medioevo: metodologie di indagine archeometrica per lo studio dell'elevato. $A r$ cheologia dell'Architettura VII:51-98.

Folk RL, Valastro Jr S. 1976. Successful technique for dating of lime mortar by carbon-14. Journal of Field Archaeology 3(2):203-8.

Gallo N. 2001. ${ }^{14} \mathrm{C}$ e archeologia del costruito: il caso di Castello Aghinolfi (MS). Archeologia dell'Architettura VI:31-6.

Heinemeier J, Jungner H, Lindroos A, Ringbom Å, von Konow T, Rud N. 1997. AMS ${ }^{14} \mathrm{C}$ dating of lime mortar. Nuclear Instruments and Methods in Physics Research B 123:487-95.

Lindroos A, Heinemeier J, Ringbom Å, Braskén M, Sveinbjörnsdóttir Á. 2007. Mortar dating using AMS ${ }^{14} \mathrm{C}$ and sequential dissolution: examples from medieval, non-hydraulic lime mortars from the Åland Islands, SW Finland. Radiocarbon 49(1):47-67.

Nawrocka D, Michniewicz J, Pawlyta J, Pazdur A. 2005. Application of radiocarbon method for dating of lime mortars. Geochronometria 24:109-15.

Pachiaudi C, Marechal J, Van Strydonck M, Dupas M, Dauchot-Dehon M. 1986. Isotopic fractionation of carbon during $\mathrm{CO}_{2}$ absorption by mortar. Radiocarbon 28(2A):691-7.

Reimer PJ, Baillie MGL, Bard E, Bayliss A, Beck JW, Bertrand CJH, Blackwell PG, Buck CE, Burr GS, Cutler KB, Damon PE, Edwards RL, Fairbanks RG, Friedrich M, Guilderson TP, Hogg AG, Hughen KA, Kromer B, McCormac G, Manning S, Bronk Ramsey C, Reimer RW, Remmele S, Southon JR, Stuiver M, Talamo S, Taylor FW, van der Plicht J, Weyhenmeyer CE. 2004. IntCal04 terrestrial radiocarbon age calibration, 0-26 cal kyr BP. Radiocarbon 46(3):102958.

Ringbom Å, Hale J, Heinemeier J, Lancaster L, Lindroos A. 2003. Dating ancient mortar. American Scientist 91(2):130-7.

Sonninen E, Jungner H. 2001. An improvement in preparation of mortar for radiocarbon dating. Radiocarbon 43(2A):271-3.

Tubbs LE, Kinder TN. 1990. The use of AMS for the dating of lime mortars. Nuclear Instruments and Methods in Physics Research B 52(3-4):438-41.

Van Strydonck M, Dupas M, Dauchot-Dehon M, Pachiaudi C, Maréchal J. 1986. The influence of contaminating (fossil) carbonate and the variations of $\delta^{13} \mathrm{C}$ in mortar dating. Radiocarbon 28(2A):702-10.

Van Strydonck M, van der Borg K, De Jong AFM, Keppens E. 1992. Radiocarbon dating of lime fractions and organic material from buildings. Radiocarbon 34(3):873-9. 